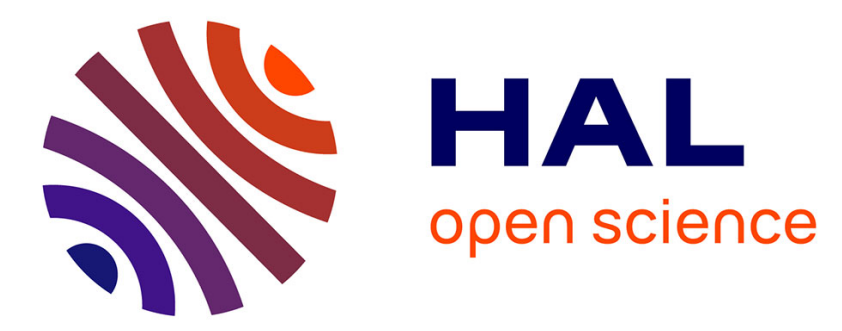

\title{
Recollection training and transfer effects in Alzheimer's disease: Effectiveness of the repetition-lag procedure
}

Benjamin Boller, Janine M Jennings, Bénédicte Dieudonné, Marc Verny, Anne-Marie Ergis

\section{- To cite this version:}

Benjamin Boller, Janine M Jennings, Bénédicte Dieudonné, Marc Verny, Anne-Marie Ergis. Recollection training and transfer effects in Alzheimer's disease: Effectiveness of the repetition-lag procedure. Brain and Cognition, 2012, 78 (2), pp.169 - 177. 10.1016/j.bandc.2011.10.011 . hal-01901238

\section{HAL Id: hal-01901238 \\ https://hal.science/hal-01901238}

Submitted on 22 Oct 2018

HAL is a multi-disciplinary open access archive for the deposit and dissemination of scientific research documents, whether they are published or not. The documents may come from teaching and research institutions in France or abroad, or from public or private research centers.
L'archive ouverte pluridisciplinaire HAL, est destinée au dépôt et à la diffusion de documents scientifiques de niveau recherche, publiés ou non, émanant des établissements d'enseignement et de recherche français ou étrangers, des laboratoires publics ou privés. 


\section{Manuscript}

Title

Recollection training and transfer effects in Alzheimer's disease: Effectiveness of the repetition-lag procedure

\section{Authors}

Benjamin Boller ${ }^{1}$, Janine M. Jennings ${ }^{2}$, Bénédicte Dieudonné ${ }^{3}$, Marc Verny ${ }^{3}$, Anne-Marie Ergis $^{1}$

${ }^{1}$ LPNCog, Institut de Psychologie, Université Paris Descartes, Paris, France,

${ }^{2}$ Department of Psychology, Wake Forest University, Winston Salem, USA,

${ }^{3}$ Centre de gériatrie, Groupe Hospitalier Pitié-Salpêtrière, AP-HP, Paris, France

\section{Correspondence should be addressed to:}

Benjamin Boller

Laboratoire de Psychologie et Neuropsychologie Cognitives

Institut de Psychologie, Université Paris Descartes

71, avenue Edouard Vaillant

92774 Boulogne-Billancourt

France

Tel: 0155205883

Fax: 0155205985

Email: benjamin.boller@parisdescartes.fr 


\section{Abstract}

Objective: This study was designed to extend the use of a memory training technique, known as the repetition-lag procedure, to Alzheimer patients. The specificity of this procedure is to target the process of recollection for improvement.

Method: A group of 12 patients were trained individually for six hours. The training procedure consisted of a series of yes / no recognition tasks in which some words were repeated throughout the test list across gradually increasing delays. Their performance was evaluated on pre-and-post tests and compared with a recognition practice group and a no contact control group.

Results: Initially, recollection training patients only performed accurately when the delay between repetitions consisted of one intervening word, but by the end of training their performance increased up to four-word intervals. Interestingly, these benefits generalized to other measures of memory, such as working memory, visual memory and source recognition. Conclusions: Effectiveness of the repetition-lag procedure in Alzheimer's disease is discussed.

\section{Keywords}

Alzheimer’s disease, Recollection, Memory training, Repetition-lag procedure, Transfer 


\section{Introduction}

Memory disorders are the earliest and most frequent deficits associated with Alzheimer's Disease (AD) (Collette, Van der Linden, Juillerat, \& Meulemans, 2003; Hodges, 2000), and they have important implications for the patients and their caregivers. Despite the severity of memory impairments and the presence of other cognitive deficits affecting executive functions and attention early in the disease, many studies that have developed memory intervention programs have shown that some benefits can be obtained in mild AD. The major intervention approaches have focused on encoding and retrieval strategy learning, multimodal intervention and process-based training (e.g. Balota, Duchek, Sergent-Marshall, \& Roediger, 2006; Clare \& Woods, 2004; Loewenstein, Acevedo, Czaja \& Duara, 2004). The outcomes of strategy learning methods show generally positive effects on the trained task, but evidence for transfer of gains to other cognitive tasks or to real life performance is limited. Multimodal approaches were developed as a response to this issue by combining different learning strategies with psychosocial interventions. Transfer effects from these programs have been found on other lab tasks and ecological measures in normal aging (e.g., Ball et al. 2002; Floyd \& Scogin, 1997) and in AD (see Clare \& Woods, 2004, for a review) but it is usually unclear which aspects of the interventions are responsible for the observed benefits. The third approach has been aimed at training specific memory processes. These programs are designed to train participants on tasks that are thought to target specific memory processes and allow one to assess transfer of gains to different untrained tasks which are thought to involve the same processes. A few studies have shown evidence of transfer benefits from process-based training in normal young and older adults (e.g. Ball \& al., 2002; Jennings, Webster, Kleykamp \& Dagenbach, 2005; Karbach \& Kray, 2009; Persson \& Reuter-Lorenz, 2008). In particular, one promising process-based training approach is the repetition-lag procedure which is considered to improve a general skill involved in recollecting specific information 
such as source, recency and output details (Jennings \& Jacoby, 2003). This training procedure is based on the dual process theory, which draws a distinction between automatic (familiarity) and controlled (recollection) memory processes (Jacoby \& Dallas, 1981; Mandler, 1980). Controlled processes are characterized by the intentional retrieval of a previously learned item and its temporo-spatial context. In contrast, familiarity refers to the automatic influences that lead to recognition of an item previously encountered without contextual details of the learning phase (e.g. Hasher \& Zacks, 1979; Posner \& Snyder, 1975; Schneider \& Shiffrin, 1977).

In the repetition-lag procedure, participants are given a series of continuous recognition tasks. They have to study a list of words and then recognize them among new words. A key feature of this procedure is the repetition of new words during the recognition phase. Each new word is presented twice throughout the recognition phase following pre-determined intervals. Participants are asked to respond "yes" to studied words and "no" to new words even if they have already encountered those new words during the task. This approach, known as the opposition procedure, was developed to separate the respective contribution of recollection and familiarity in the same task. The first presentation of new words during the recognition task is supposed to increase their familiarity, and participants can misattribute this familiarity to the prior study phase, confuse repeated words with studied words, and mistakenly respond "yes". However, if participants are able to recollect the source of a repeated word's presentation, then any influence of familiarity will be removed and they will correctly respond "no" (e.g. Jacoby, Yonelinas, \& Jennings, 1997; Jennings \& Jacoby, 1993, 1997; Yonelinas, 2002). A second important feature of the repetition-lag procedure is the gradual increase of the lag intervals across training sessions as performance improves. The number of intervening words between the first and the second presentation of repeated words are modulated by the level of performance success. This incremented-difficulty aspect of the training technique was designed to improve recollection by extending what participants do to 
successfully recollect information at a short interval so that it is applied at longer delays (Jennings \& Jacoby, 2003, Jennings et al., 2005).

As mentioned, the repetition-lag training technique was based on the opposition procedure or exclusion task, which is part of the larger process dissociation procedure (Jacoby, 1991; Jacoby, Toth, \& Yonelinas, 1993; Jacoby, Yonelinas, \& Jennings, 1997; Jennings \& Jacoby, 1993, 1997; Yonelinas, 2002). Jacoby (1991, 1998) developed the process-dissociation procedure (PDP) in order to separate and quantify the contributions of controlled and automatic processes to performance in a single memory task and it has been used in several studies to examine changes in memory processes in normal aging and in AD. Results have shown that normal aging affects consciously controlled memory processing but spares automatic memory processes (Anderson, Ebert, Jennings, Grady, Cabeza \& Graham 2008; Hay \& Jacoby, 1999; Jennings \& Jacoby, 1993, 1997; Titov \& Knight, 1997). This dissociation is even more marked in Alzheimer's disease which has been characterized by an early impairment of controlled processes (Adam, Van der Linden, Collette, \& Salmon, 2005; Knight, 1998; Koivisto, Portin, Seinelä \& Rinne, 1998; Smith \& Knight, 2002) and an initial preservation of automatic processes (Adam et al., 2005; Koivisto \& al., 1998). In addition, the same pattern of results has been highlighted in individuals with amnestic mild cognitive impairment (aMCI), a stage considered to be transitional between healthy aging and $\mathrm{AD}$ (Anderson et al., 2008).

In view of these findings, use of the repetition-lag procedure to target consciously controlled processing for improvement in normal aging, MCI and AD would appear to be a beneficial approach. Thus far, results of this training have shown that memory performance can be improved in cognitively healthy older adults (Jennings \& Jacoby, 2003). In that work, initially, participants could only accurately identify repeated items when the delay between repetitions consisted of 2 intervening words, but by the end of six hours of training, they could perform accurately at 28 word-intervals. Moreover, post-training gains following 
recollection training were found on measures of working memory, memory monitoring, processing speed and long term memory in both cognitively healthy older adults (Jennings et al., 2005) and in individuals with MCI (Jennings et al., 2006).

The current study was designed to extend the use of the repetition-lag procedure to patients with mild $\mathrm{AD}$. Our assumption is that this training procedure could improve the ability to recollect specific information in AD. Even if controlled processes are impaired in this disease, they are not completely non-functional, especially at early stages and might be enhanced by this procedure. Improvements in AD patients were expected on the training task itself and on other memory measures as has been demonstrated in normal aging and individuals with MCI (Jacoby \& Jennings, 2003; Jennings et al., 2005, 2006). Our first objective then was to verify whether $\mathrm{AD}$ patients can improve their performance on the training task if it is adapted to the specificities of their cognitive deficits. Our second objective was to examine whether gains on transfer tasks can be observed if $\mathrm{AD}$ patients show improvement on the training task itself. For that purpose pre-and-post training tests were administered to a recollection training group and to two control groups (recognition practice and no contact). These tests consisted of tasks assessing working memory (n-back and reading span) and episodic memory (recall, item-recognition memory and source-recognition memory) in verbal and visual modalities and were chosen for their abilities to target the same processes as those involved in the training task. The n-back and reading span tasks were selected because they involve controlled working memory processes, respectively updating and attentional control processes; the recall and recognition tasks were selected because they involve both recollection and familiarity. As the goal of repetition-lag procedure is to improve the ability to recollect information across increasing delay intervals, we hypothesized that the training procedure would benefit these working and episodic memory measures. No improvement is expected in both recognition practice and no contact groups on any of the transfer tasks. 


\section{Methods}

\subsection{Participants}

Thirty-six community-dwelling patients with $\mathrm{AD}$ volunteered to take part in the current study and were recruited from the Geriatric Center of Pitié-Salpêtrière Hospital. The diagnosis of dementia was based on general medical, neurological, and neuropsychological examinations according to the National Institute of Neurological and Communication Disorders - Alzheimer's Disease and Related Disorders Association (NINCDS-ADRDA) criteria for probable Alzheimer's disease (McKahnn et al., 1984) and the DSM IV clinical criteria for dementia of the Alzheimer type (APA, 1994). Patients were included if the severity of AD was mild or mild-to-moderate as indicated by a score of 19 or above on the Mini-Mental State Evaluation (MMSE, Folstein, Folstein, \& McHugh, 1975). Patients were excluded if they had a history of clinically significant depression, alcohol or drug use, other neurological disease, traumatic brain damage or if French was not their primary language. The 36 patients were randomly divided into 3 groups - an experimental recollection training group, a control recognition practice group and a no contact group. Each group consisted of eight females and four males except for the no contact group ( 7 females and 5 males). The demographic and neuropsychological characteristics of all patients are presented in Table 1. The clinical assessment included the Geriatric Depression Scale (GDS) for documentation of depressive symptoms (Yesavage et al., 1983). The MMSE and the Mattis Dementia Rating Scale (MDRS; Mattis, 1974) were used to assess global functioning and dementia severity. The neuropsychological battery included measures of memory (Digit span subtest of the Wechsler Adult Intelligence Scale - III; Wechsler, 1997), language (Verbal fluency; Cardébat et al., 1990; DO80 picture naming test; Deloche \& Hannequin, 1997), and executive functions (Trail Making Test A and B; Adjutant General's Office, 1944). No significant differences 
were found in age, years of education, cognitive global functioning or neuropsychological assessments between the three groups.

Please insert Table 1 about here

\subsection{Materials}

\subsubsection{Training Tasks}

The two different training tasks both consisted of verbal yes/no recognition tasks. The words were written in French and presented one at a time in the center of a laptop computer screen for 3 seconds followed by a 1 second white screen. Each training session consisted of a study phase with 16 words to learn and a test phase where the study words were mixed with 36 other words.

\subsubsection{Recollection Training}

This training was adapted from the repetition-lag procedure developed by Jennings and Jacoby (2003). Seven hundred and sixty-eight concrete nouns chosen from Bonin's database were randomly divided into 48 sets of 16 words (Bonin et al., 2003). These lists were matched for frequency of occurrence in the language. Twenty-four lists were used as study items for the training sessions. The remaining lists were used as distractor items for the recognition phase. Patients were given four training sessions a day, three days per week for two weeks. Each training session consisted of a study and a test phase, which is illustrated in Figure 1. During the study phase, patients were asked to read the words aloud and remember them. In the test phase, patients were shown the 16 study words and 16 new words with the 16 new words repeated at one of two different lags (number of intervening items between the first and second presentation of a repeated word). The task was to recognize the words they had read 
aloud from the study phase (i.e., responding yes to study words and no to new items even when they were repeated). The experimenters gave positive feedback only when patients responded correctly. The test phase was not limited by time, and each of the four sessions required about 7 to 10 minutes.

The incrementing procedure was implemented by gradually increasing the lag intervals according to the patient's level of success. The criterion for success was set to a maximum of two errors in identifying the repeated words. Specifically, in the first session, the 16 new words were repeated after two different lag intervals: 8 words after 1 intervening word (Lag 1) and 8 words after 2 intervening words (Lag 2). The lag interval pairs used for training consisted of 1 and 2; 1 and 3;2 and 4; 2 and 8 and 4 and 12. These pairs were chosen so that patients were always working at one lag interval they had already mastered and a second interval that was new and more difficult. If participants did not achieve criterion at both lags, they continued to work at those intervals for as many sessions as needed to meet criterion. Once criterion was reached the lag intervals increased in the order listed above. Gains in performance were measured by comparing the length of interval at which patients reached criterion by the end of Session 3 on the first day of training with the longest lag interval reached by the end of the six-day procedure. Sessions 1 and 2 on the first training day were considered as a required practice to allow patients to become familiar with the mechanics of the procedure.

Please insert Figure 1 about here

\subsubsection{Recognition Practice}

This procedure was adapted from a cognitive training control condition judged to be comparable in time, effort, and social stimulation to the repetition-lag technique (Jennings et 
al., 2005). One thousand, one hundred and fifty-two concrete nouns chosen from the Brulex database (Content, Mousty, \& Radeau, 1990) were randomly divided into 72 sets of 16 words. These sets were matched for frequency of occurrence in the language. They were then organized into 24 study and 48 test lists. As in the recollection training group, patients were given four training sessions a day, three days per week for two weeks. In each session, they were asked to read the 16 words aloud and learn them for the recognition test that would follow. During the test phase they had to recognize the 16 study words which were mixed with 32 new words. Experimenters gave positive feedback to the patients only when they responded correctly. The test phase was not limited by time, and each of the four sessions required about 7 to 10 minutes.

\subsubsection{Transfer Tasks}

\subsubsection{N-Back Task}

This task is a modified version of the parametric n-back task (Jennings et al., 2005; Jonides et al., 1997) developed by Dobbs and Rule (1989). The consonants "b, d, f, g, h, j, m, $\mathrm{n}, \mathrm{q}, \mathrm{r}$, and $\mathrm{t}$ " acted as stimuli and were presented in upper or lowercase. Each letter was presented for 2 seconds in the center of a laptop computer screen and followed by a 1 second blank screen. Patients were shown a sequence of letters, and for each one they had to decide whether it matched the identity of the letter that had preceded it by $n$ places in the sequence. The task started with the 1-back sequence, followed by the 2-back sequence and then the 3 back sequence. A sequence was composed of 35 trials in which only 10 trials were used to evaluate performance. These 10 critical trials corresponded to 7 trials in which the letters matched the n-back position and 3 trials in which the letters matched near the n-back position (for the 1-back condition, 2 trials occurred in the 2-back position and 1 trial in the 3-back position; for 2-back, 2 trials occurred in the 1-back position and 1 trial in the 3-back position; for 3-back, 2 trials occurred in the 1-back position and 1 trial in the 2-back position). Twenty- 
five no-matched trials completed the sequence. In these no-matched trials, letters were spaced between an identical letter by at least eight trials. Prior to starting each n-back level, a practice sequence was carried out to ensure the instructions were understood.

\subsubsection{Reading Span Task}

Patients were given a French version of the reading span task (Desmette, Hupet, Schelstraete, \& Van der Linden, 1995) adapted from Daneman and Carpenter's task (1980). Sixty-two sentences were presented one at time on a laptop computer screen. Participants had to read aloud lists of sentences and memorize the final word of each one. The number of sentences in a passage increased from one to six with three trials at each series length. The

target measure was the highest span correctly recalled for two out of three trials. Prior to starting the task, a practice trial of two sentences was conducted to ensure the instructions were clear.

\subsubsection{RL/RI 16: Free and Cued Recall Task}

This episodic memory task is a French version of a visual verbal learning test (Van der Linden, Coyette, Poitrenaud \& GREMEM, 2004) adapted from Grober and Buschke's procedure (1987) to assess episodic memory. This test consisted of 16 to-be-learned words with an immediate cued recall test in order to control encoding, three free recall tests, each immediately followed by cued recall for items not retrieved at free recall, a yes-no recognition task and a 20 minute delay free and cued recall test. The study words belong to different semantic categories, which are used as cues.

\subsubsection{DMS 48: Delayed Matching-to-Sample Task}

This task is a visual forced-choice recognition memory task adapted from Barbeau et al. (2004). Stimuli consisted of colored drawings of abstract patterns and concrete objects. During the encoding phase, patients were asked to consecutively look at 48 pictures presented 
at a 3 second rate on a laptop computer screen, and to remember them. The study phase was followed by a counting backward interference task lasting 20 seconds. For the recognition task each of the 48 targets was presented simultaneously with a distractor and the patients were asked to identify the target.

\subsubsection{Source Recognition Task}

Sixty pictures were selected from Snodgrass and Vanderwart's norms (1980). The materials consisted of the sixty pictures, with an average level of visual complexity $(2.59 \pm$ $.67)$, and their corresponding names. For the study phase, a set of 30 stimuli was constructed consisting of 15 words and 15 pictures. The 30 targets and 30 new stimuli were used for the recognition task in both their picture and their word format. During the study phase the stimuli were presented successively one at a time in random order via a laptop computer at a 3 second rate. Patients were asked to try to remember them for a later memory test. After a 20 second counting backward interference task, a series of 30 stimulus cards was presented. Each one contained a target word and its pictorial representation plus a distractor word and its pictorial representation. Patients were required to identify the target and indicate whether it was originally presented as a word or a picture.

\subsection{Procedure}

Patients were tested individually for the pre-and-post training assessments and administered the training procedures in their own homes except for six individuals ( 3 from the recollection training group and 3 from the recognition practice group) who were assessed and trained in the geriatric centre. The pre-and-post training tests were administered the first and the fourth weeks in the same following order: 1) RL/RI 16: three trials of free and cued recall 2) RL/RI 16: recognition, 3) DMS 48, 4) N-back: 1-back, 2-back then 3-back, 5) RL/RI 16: delay free and cued recall, 6) source recognition task, and 7) reading span task. Parallel forms 
of the source recognition, DMS 48 and RL/RI 16 tasks were used across the pre-and-post training sessions and counterbalanced across patients. The recollection training and recognition practice procedures were administered 1 hour a day, three days a week for two weeks. During this period, the no contact group had no interaction with the experimenters.

\section{Results}

\subsection{Training Tasks}

\subsubsection{Recollection Training}

In order to assess the effectiveness of recollection training, the interval length at which criterion was achieved between the first and last days of training were compared using a paired sample $t$-test (see Figure 2). Results showed a significant improvement between the first and the last training day, $t(11)=-6.77, p<.001$. On the first day of training, patients reached criterion with an average lag interval of 1.33 intervening items $(\mathrm{SD}=.49)$ but by the last day of training, they were able to reach criterion with an average of 5 intervening items $(S D=1.81)$.

Please insert Figure 2 about here

Please insert Table 2 about here

To ensure that the improvements in performance obtained with the repetition-lag procedure were due to recollection, analyses examining changes in recognition performance and response bias during the course of training were carried out. Recognition accuracy was determined by taking the average level of performance across the four training lists for each 
training day and calculating the difference between the probability of responding "yes" to study items (hits) and new items on their first presentation (false alarms). These results are reported in Table 2. A one-way repeated measures ANOVA conducted with day as the variable of interest found no significant change in recognition accuracy, $F(5,282)<1$, replicating results obtained elsewhere (Jennings \& Jacoby, 2003). This finding suggests that patients' improvements in identifying repeated items across increasingly longer intervals was not simply an artifact arising from general practice effects but was instead specific to changes in processes associated with recollection.

As mentioned, an analysis of response bias was also conducted as patients may have noticed across training that there were twice as many "no" responses as "yes" responses per trial (16 new items and 16 repeated items of 48 stimuli) and adapted their responses accordingly. Response bias was determined by calculating the index C (Macmillan \& Creelman, 2005; Snodgrass \& Corwin, 1988), which locates the bias criterion relative to the intersection of old and new distributions, from the hits and false alarm data described above. A value of 0 for $\mathrm{C}$ indicates a neutral response bias, a positive value indicates a conservative response bias and a negative value indicates a liberal response bias. $\mathrm{C}$ estimates are reported in Table 2. A one-way repeated measures ANOVA was conducted with day as the independent variable and showed no significant change in response bias across the days, $F(5$, $282)<1$.

\subsubsection{Recognition Practice}

In order to evaluate whether patients showed any gains in the recognition training task, performance was established by calculating the average level of accuracy across the four training lists for each training day. Accuracy level was determined by the difference between the probability of responding "yes" to study items (hits) and new items (false alarms). Results are reported in Table 3. A one-way repeated measures ANOVA was conducted with day as 
the variable of interest. The results showed no significant change in recognition accuracy across the days, $F(5,282)<1$.

Please insert Table 3 about here

\subsection{Transfer Tasks}

In order to assess the effects of training on the transfer tasks, a multivariate analysis of variance (MANOVA) was first conducted on the pre-training test scores to ensure that the performance of the three groups were statistically equivalent before training. The results showed no significant effect of group, Wilks' $F(22,46)<1$. Then, a 3 (group) x 2 (test time) mixed factor MANOVA was carried out on the pre and post training tests for the three groups to examine the effectiveness of the repetition-lag procedure. As expected, there was no main effect of group, Wilks' $F(22,46)=1.50$, ns, but a significant group x test interaction, Wilks' $F(22,46)=1.96, p=.03$, and a significant main effect of test session, Wilks' $F(11,23)=$ 235.08, $p<.001$, were found. Finally, a series of 3 (group) x 2 (test time) mixed factor ANOVAs was carried out for each pre and post training test for all three groups; no significant group effect was found for any of the transfer measures (all $F^{\prime}$ s $<2.22$, all $p$ 's $>$ .12). Each significant interaction was followed by paired sample $t$-tests comparing pre-andpost training performance within each group. Test main effects and group $\mathrm{x}$ test time interactions are described below: all results are summarized in Table 4. 


\subsubsection{N-back Task}

The N-back performance was determined by the difference between the N-back matched trials correctly identified (hits) and the near N-back matched trials incorrectly identified as matched (false alarms). Results from the 1-back and 3-back tasks showed no significant group x test interaction, respectively $F(2,33)=0.12, p=.89$ and $F(2,33)=0.69, p=.51$. In contrast, a significant group by test interaction was found for the 2-back task, $F(2,33)=4.24$, $p=.02, \eta_{\mathrm{p}}{ }^{2}=.20$. The recollection training group improved significantly on the post training test of 2-back task performance, $t(11)=4.10, p=.002$, whereas no improvements were found in the other two groups (t's $\leq .92, \mathrm{p}$ 's $\geq .37$ ).

\subsubsection{Reading Span Task}

There was no significant test effect, $F(1,33)<1$ nor significant group $\mathrm{x}$ test interaction, $F(2,33)<1$ for the reading span task. Performance appears unaffected by the training procedure.

\subsubsection{RL/RI 16 Free and Cued Recall Task}

No significant test effects or significant group $\mathrm{x}$ test interactions were found on any of the immediate free recall and cued recall tasks, or delayed free and cued recall tests, respectively all $F(1,33)<1$ and all $F(2,33)<1$. In contrast, a significant test effect, $F(1,33)=1.50, p=$ $.012, \eta_{\mathrm{p}}{ }^{2}=.31$ and a significant group $\mathrm{x}$ test interaction, $F(2,33)=14.87, p<.001, \eta_{\mathrm{p}}{ }^{2}=.23$ were found on the recognition subtest. Subsequent analyses performed with paired sample $t$ tests revealed a significant gain in performance for both the recollection training and recognition practice groups, respectively $t(11)=2.59, p=.03$ and $t(11)=4.02, p=.002$, which was not seen in the no contact group, $t(11)=.56, p=.586$. 


\subsubsection{DMS 48 Task}

The DMS 48 measure was determined by computing the number of correctly recognized items. The 3 (group) x 2 (test time) ANOVA revealed a significant group $\mathrm{x}$ test interaction, $F(2,33)=11.14, p<.001, \eta_{\mathrm{p}}{ }^{2}=.40$. Paired sample $t$-tests showed that only the recollection training group significantly improved performance at post test, $t(11)=4.85, p<.001$, whereas the other two groups did not (t's $\leq 1.24$, p's $\geq .24$ ).

\subsubsection{Source Recognition Task}

The source recognition measure was determined by computing the number of items correctly recognized in the format presented during the study phase and a significant group $\mathrm{x}$ test interaction was found, $F(2,33)=10.09 ; p<.001, \eta_{\mathrm{p}}^{2}=.38$. Paired sample $t$-tests showed that only the recollection training group's performance improved significantly on the post test, $t(11)=4.05, p=.002$, whereas the performance of the other two groups did not change $($ t's $\leq 1.83$, p's $\geq .09)$.

\section{Discussion}

The results of the present study are remarkable in two ways: 1) they are the first to show that the repetition-lag procedure has a beneficial effect on recollection memory in AD patients and 2) this effect is transferable to other memory tasks as has been evidenced in normal aging and in MCI individuals (Jennings \& Jacoby 2003; Jennings et al., 2005, 2006). At the beginning of training, patients from the recollection training group were able to identify accurately a repeated word only when an average of 1 intervening word occurred between the first and second presentation of the repeated word. However, after six 1-hour training sessions, patients were able to reach criterion after a delay of 4 to 8 intervening words. At the same time, recognition performance measured as the difference between hits ("yes" responses 
to studied items) and false alarms ("yes" responses to unstudied words on their first presentation) was not improved by the training. This result suggests that effectiveness of the repetition-lag procedure does not lie with a general practice effect but is more specific to the form of memory necessary to identify repeated occurrences of a previously presented word. An alternative explanation for such improvement could involve a preserved metamemorial ability in AD patients that allowed them to shift their response bias (Waring, Chong, Wolk, \& Budson, 2008) to increasingly respond "no" to all test items thus rejecting repeated items with greater frequency. However, as no change was observed on response bias across training, increases in conservative responding could not explain why only memory for unstudied repeated words was improved.

Our analysis of response bias did yield one somewhat unexpected result for the recollection training group on the repetition-lag training task. Specifically, a conservative response bias (values of $\mathrm{C}$ greater than 0) was shown by the group. Although it is widely acknowledged that AD patients show a more liberal response bias compared with healthy older adults (see Budson, Wolk, Chong \& Waring, 2006, for a review). This result may have occurred because of the design characteristics of the repetition-lag procedure such that the training experimental recognition tasks differed in some points from the ones traditionally used to evaluate response bias in this population. In particular, the number of studied words was shorter; the presentation time of each studied words was longer and there were no interfering tasks between the study and test phases. Nonetheless, when compared to cognitively healthy older adults administered the repetition-lag procedure (see Jennings \& Jacoby, 2003), the AD patients' response bias is markedly less conservative, which seems somewhat consistent with other findings (e.g. Budson et al., 2006).

The repetition-lag procedure seems to draw its efficacy from two key features: one is the opposition procedure which targets recollection in order to correctly identify repeated items. The second is the incremented-difficulty approach that allows one to enhance the ability to 
recollect information across increasing delay intervals. Indeed, as the number and the length of training sessions were similar in both the recollection training and recognition practice groups, the observed improvements seem to be linked to the nature of the repetition-lag task which both requires recollection and takes into account individual performance by gradually increasing the lag intervals as performance improves. However, theses gains were less marked than those reported in MCI individuals (from 2 to 14 intervening words, Jennings et al., 2006) and in older adults (2 to 28, Jennings \& Jacoby, 2003; 2 to 18, Jennings et al., 2005). Given a similar number of training sessions were used as in all the studies above, these differences can be explained by the greater level of recollection deterioration in AD than in the MCI stage or in normal aging (e.g. Adam et al., 2005; Anderson et al. 2009; Jennings \& Jacoby, 1993), which may have necessitated more training to achieve comparable gains as obtained in populations with better recollection. Nonetheless, the improvements seen here are in line with our general assumption that even though controlled processes are impaired in $\mathrm{AD}$, a residual part of controlled processing remains sufficiently functional to be enhanced by a specific training focus.

Moreover, post training gains were found on other measures of memory in the recollection training group. AD patients from this group demonstrated significantly greater post-training scores relative to pre-training for the visual recognition task (DMS 48), the source recognition task, and the 2-back task, a working memory task assessing the updating executive component of the central executive. No significant improvements were found on these tasks in the recognition practice and the no contact control groups. Likewise, no significant improvements were seen in any of the three groups on the reading span, 1-back, 3-back nor the RL/RI 16 free and cued recall tasks.

The improvements observed on the visual and source recognition tasks in the recollection training group may be linked to the patients' increased capacity to retrieve associative information after repetition-lag training. According to Moscovitch's model of memory 
(1992), the content of memories includes individual pieces of information (item memory), and links between those pieces of information (associative memory). Dual-process models of recognition provide a framework that takes into account this distinction. Item memory can be supported by both recollection and familiarity influences whereas associative memory seems to be more recollection specific. Because associative memory is highly reliant on recall-like processes at retrieval it seems that the aspects of memory that are enhanced by the repetitionlag procedure are the ones that involve associative memory. This hypothesis is in line with the absence of any improvements in free recall on the RL/RI 16 task and on the reading span task which do not require associative memory for successful performance. However, this hypothesis cannot explain the absence of any improvements in cued recall on the RL/RI 16 task. Considering that the cued recall task requires more cognitive resource than recognition, and that patients with mild $\mathrm{AD}$ are more impaired in cued recall tasks than in recognition tasks (Tounsi et al., 1999), one explanation could be that the transfer effects are too subtle to be observed in cued recall tests. Moreover, cued recall involves also semantic memory, which is precociously impaired in AD (Hodges, \& Patterson, 1995). A surprising result was found on the recognition measure of the RL/RI 16 free and cued recall task. The recollection training and the recognition practice groups both showed a significant improvement after training whereas the no-contact group did not. If the improvement observed in the recollection training group can be attributed to the effect of the repetition-lag procedure, the improvement observed in the recognition practice group seems more likely linked to the nature of that training task itself. Indeed, the recognition practice training task's demands were very close to those of the RL/RI 16's recognition test. Both consist of a verbal yes / no recognition task and a task-specific effect from the recognition practice technique is not difficult to envisage.

As for the improvements observed on the 2-back task in the recollection training group these may reflect the enhancement of updating processes. This hypothesis could explain the absence of improvement on the reading span task which involves attentional controlled 
processes rather than updating processes. Recollection training with increasing lags could thus enhance performance in the 2-back task because it taps the specific strategies required to initiate a strategic retrieval search and check that information has been correctly recalled. Recollection training may also contribute to the enhancement of temporal order memory, which is relevant for successful 2-back performance. The absence of any improvements on the 1-back and the 3-back levels compared to the significant improvements found on the 2back level could be attributed to floor and ceiling effects: The 1-back task was too easy whereas the 3-back task was too difficult for AD patients.

In summary, the effects on the working and episodic memory tasks may be understood by the improvement of recollection. It seems that the repetition-lag procedure does not improve a memory system per se but may enhance specific processes involved in different memory systems. The gains found on the n-back, visual recognition and source recognition tasks indicate that the repetition-lag procedure provides transfer effects on recognition tasks, in both yes / no and forced choice modalities for different categories of stimuli such as drawings, nouns or letters. These benefits suggest that this procedure is targeting recollection and may be an effective method for promoting training and transfer in AD.

Nevertheless, all these results should be interpreted with caution because of the small sample size of the patients. Other studies need to be conducted in order to replicate these findings in a more representative group. Even though the recognition practice condition has been chosen because it was judged to be comparable with recollection training in time, effort, and social stimulation, one possible interpretation could be that repetition-lag procedure is harder than the recognition practice one. Thus, the benefits would not be specifically attributable to training with a lag procedure.

However, theses gains are in line with previous studies that have shown effective cognitive training and successful transfer in normal aging (Ball et al., 2002; Jennings et al., 2005) and provide evidence that individualized cognitive training programs can produce 
transfer effects in AD. These transfer effects are even more striking considering the paucity of evidence for successful training and transfer effects from cognitive training programs that do not rely on mnemonics or errorless learning techniques in $\mathrm{AD}$ patients (for review see Clare \& Woods, 2004).

It is now widely acknowledged that laboratory measures of recollection correlate strongly with the self-reported frequency of everyday memory errors such as repeating oneself or forgetting if medication has been already taken (Jacoby, Jennings, \& Hay, 1996). The recollection training procedure may have a positive effect on everyday memory functioning and should be an approach for further such research.

Future research could also make use of functional neuroimaging to determine whether the benefits observed from the repetition-lag procedure in $\mathrm{AD}$ patients are accompanied by changes in neural activity. Data from neuroimaging have yielded evidence for the compensation hypothesis of age-related hemispheric asymmetry reductions which have been use to explain why high-performing older adults can do as well as young adults on verbal recall and source memory tasks (Cabeza, Anderson, Locantore \& McIntosh, 2002) suggesting these participants respond to the retrieval demands of the memory task by recruiting bilateral prefrontal cortex regions (PFC). This compensation hypothesis has also been applied to highperforming MCI individuals. A bilateral PFC activation has been observed in these individuals on a verbal episodic memory encoding task and could explain the absence of differences in performance relative to older control adults (Clément \& Belleville, 2010). Moreover, other research has shown that recollection relies on the PFC and is involved in several working and long-term memory tasks (for review see Yonelinas, 2002) and neural correlates have been reported after training-related improvement in normal aging (Nyberg et al., 2003) and in individuals with MCI (Belleville et al., 2011). So, one assumption could be that the repetition-lag procedure may produce changes in $\mathrm{AD}$ according to the compensation hypothesis. 
Alternative explanations for the training gains found here should also be considered in future studies particularly in light of data presented by Ally, Gold and Budson (2009), who used a receiver operating characteristics paradigm (ROC) to examine familiarity and recollection in $\mathrm{AD}$. They found recollection to be near 0 and familiarity to be markedly impaired. Although the integrity of familiarity appears to be a matter of dispute across the literature with some work showing normal familiarity (Westerberg et al., 2006), deficits in recollection appear inarguable (Adam, Van der Linden, Collette, \& Salmon, 2005; Knight, 1998; Koivisto, Portin, Seinelä \& Rinne, 1998; Smith \& Knight, 2002). It was for the latter reason that the repetition-lag procedure was adapted to make use of study/test lists that were significantly shorter than those used elsewhere (e.g., Ally et al., 2009; Jennings et al., 2005) in the hope that use of some residual capabilities associated with recollection could be tapped by patients and facilitated. Nonetheless, recollection estimates of 0 (Ally, Gold \& Budson, 2009) raise the question as to whether aspects of memory processing other than recollection may have been improved. Given the gains observed on the 2-back and recognition part of the free and cued recall tasks, and the fact that these two transfer tasks and the experimental training all involve a yes/no recognition memory procedure, which can rely heavily on familiarity (Westerberg \& al., 2006), it is possible that participants may have learned to alter or suppress responding on the basis of familiarity in a manner that enhanced task performance.

In addition, recent studies have established factors that may optimize repetition-lag procedure effects in normal aging. The self-initiation of controlled processes on an openended, intentional encoding task was highly correlated with improvements on the training task (Bissig \& Lustig, 2007). Furthermore, a more recent study has demonstrated that strategies encouraging older adults to spend sufficient time and attention at encoding can improve performance on recognition memory transfer tests (Lustig \& Flegal, 2008). Future research needs to take into account these recent findings to explore whether these factors could be relevant to successful cognitive training in $\mathrm{AD}$. 


\section{Acknowledgements}

This work was supported by the Interdisciplinary Research Program (PIR) No. SUB/2008/0133/DR16 titled "Longévité et Vieillissement", from the Centre National de la Recherche Scientifique (CNRS).

\section{References}

Adam, S., Van der Linden, M., Collette, F., \& Salmon, E. (2005). Further exploration of controlled and automatic memory processes in early Alzheimer's disease. Neuropsychology, 19, 420-427.

Adjutant General's Office. (1944). Army individual test battery: Manual of directions and scoring. Washington, DC: War Department.

Ally, B. A., Gold, C. A., \& Budson, A. E. (2009). An evaluation of recollection and familiarity in Alzheimer's disease and mild cognitive impairment using receiver operating characteristics. Brain and Cognition, 69, 504-513.

American Psychiatric Association (1994). Diagnostic and statistical manual of mental disorders - fourth edition. Washington, DC: American Psychiatric Association.

Anderson, N. D., Ebert, P. L., Jennings, J. M., Grady, C. L., Cabeza, R., \& Graham, S. J. (2008). Recollectionand familiarity-based memory in healthy aging and amnestic mild cognitive impairment. Neuropsychology, 22, $177-187$

Ball, K., Berch, D. B., Helmers, K. F., Jobe, J. B., Leveck, M. D., Marsiske, M., Morris, J. N., et al. (2002). Effects of cognitive training interventions with older adults: a randomized controlled trial. Journal of the American Medical Association, 288, 2271-2281.

Balota, D.A., Duchek, J.M., Sergent-Marshall, S.D., \& Roediger, H.L.,III. (2006). Does expanded retrieval produce benefits over equal interval spacing? Explorations of spacing effects in healthy aging and early stage Alzheimer's disease. Psychology and Aging, 21, 19-31.

Barbeau, E., Didic, M., Tramoni, E., Felician, O., Joubert, S., Sontheimer, A., Ceccaldi, M., \& Poncet, M. (2004). Evaluation of visual recognition memory in MCI patients. Neurology, 62, 1317-1322.

Barbeau, E., Tramoni, E., Joubert, S., Mancini, J., Ceccaldi, M., \& Poncet, M. (2004). Evaluation de la mémoire de reconnaissance visuelle : normalisation d'une nouvelle épreuve en choix forcé (DMS 48) et utilité en 
neuropsychologie clinique. In M. Van der Linden, S Adam, A. Agniel \& les membres du GRENEM (Eds.). L'évaluation des troubles de la mémoire. Présentation de quatre tests de mémoire épisodique (avec leur étalonnage) (pp. 25-47). Marseille : Solal.

Belleville, S., Clément, F., Mellah, S., Gilbert, B., Fontaine, F., \& Gauthier, S. (2011). Training-related brain plasticity in subjects at risk of developing Alzheimer's disease. Brain, 134; 1623-1634.

Bissig, D., \& Lustig, C. (2007). Who benefits from memory training? Psychological Science, 18, 720-726.

Bonin, P., Méot, A., Aubert, L., Malardier, N., Niedenthal, P., \& Capelle-Toczek, M.C. (2003). Normes de concrétude, de valeur d'imagerie, de fréquence subjective et de valence émotionnelle pour 867 mots [Concreteness, imageability, subjective frequency and emotional valence norms for 867 words]. L'Année Psychologique, 104, 655-964.

Budson, A.E., Wolk, D.A., Chong, H., \& Waring (2006). Episodic memory in Alzheimer's disease: Separating response bias from discrimination. Neuropsychologia, 44, 2222-2232.

Cabeza, R., Anderson, N. D., Locantore, J. K., \& McIntosh, A. R. (2002). Aging gracefully: compensatory brain activity in high-performing older adults. NeuroImage, 17, 1394-1402.

Cardébat, D., Doyon, B., Puel, M., Goulet, P., \& Joanette, Y. (1990). Evocation lexicale formelle et sémantique chez des sujets normaux : performances dynamiques de production en fonction du sexe, de l'âge et du niveau d'études. Acta Neurologica Belgica, 90, 207-217.

Clare, L. \& Woods, R. T. (2004). Cognitive training and cognitive rehabilitation for people with early-stage Alzheimer's disease: a review. Neuropsychological Rehabilitation, 14, 345-401.

Clément, F., \& Belleville, S. (2010). Compensation and disease severity on the memory-related activations in mild cognitive impairment. Biological Psychiatry, 68; 894-902.

Collette, F., Van der Linden, M., Juillerat, A. C., \& Meulemans, T. (2003). Cognitive neuropsychological aspects. In R. Mulligan, M. Van der Linden, \& A. C. Juillerat (Eds.), The clinical management of early Alzheimer's disease (pp. 35-73). Mahwah, NJ: Lawrence Erlbaum Associates.

Content, A., Mousty, P., \& Radeau, M. (1990). Brulex : Une base de données lexicales informatisée pour le français écrit et parlé [Brulex: A lexical database for written and spoken French]. L'Année Psychologique, $90,551-566$.

Daneman, M., \& Carpenter, P. A. (1980). Individual differences in working memory and reading. Journal of Verbal Learning and Verbal Behavior, 19, 450-466. 
Deloche, G., Hannequin, D. (1997). Test de dénomination orale d'images. DO80. Paris: Edition du Centre de Psychologie Appliquée.

Desmette, D., Hupet, M., Schelstraete, M.A. \& Van der Linden, M. (1995). Adaptation en langue française du "Reading Span Test" de Daneman et Carpenter (1980). L'Année Psychologique, 95, 459-482.

Dobbs, A.R., \& Rule, B.G. (1989). Adult age-differences in working memory. Psychology and Aging, 4, 500503.

Floyd, M., \& Scogin, F. (1997). Effects of memory training on the subjective memory functioning and on mental health of older adults: A meta-analysis. Psychology and Aging, 12, 150-161.

Folstein, M.F., Folstein, S.E., \& McHugh, P.R. (1975). "Mini-mental state": A practical method for grading the cognitive state of patients for the clinician. Journal of Psychiatric Research, 12, 189-198.

Grober, E., \& Buschke, H. (1987). Genuine memory deficits in dementia. Developmental Psychology, 3, 13-36.

Hasher, L., \& Zacks, R. T. (1979). Automatic and effortful processes in memory. Journal of Experimental Psychology General, 108, 356-388.

Hay, J.F., \& Jacoby, L.L. (1999). Separating habit and recollection in young and older adults: Effects of elaborative processing and distinctiveness. Psychology and Aging, 14, 122-134.

Hodges, J. R. (2000). Memory in the dementias. In E. Tulving, \& F. I. M. Craik (Eds.), The Oxford handbook of memory (pp. 441-459). New York: Oxford University Press.

Hodges, J.R., \& Patterson, K. (1995). Is semantic consistently impaired early in the course of Alzheimer's disease ? Neuroanatomical and diagnostic implications. Neuropsychologia, 33, 441-459.

Jacoby, L.L. (1991). A process dissociation framework : Separating automatic from intentional uses of memory. Journal of memory and Language, 30, 513-541.

Jacoby, L.L. (1998). Invariance in automatic influences of memory : Toward a user's guide for the ProcessDissociation Procedure. Journal of Experimental Psychology: Learning, Memory, and Cognition, 24, 3-26.

Jacoby, L.L., \& Dallas, M. (1981). On the relationship between autobiographical memory and perceptual learning. Journal of Experimental Psychology: General, 118, 126-135.

Jacoby, L.L., Jennings, J.M. \& Hay, J.F. (1996). Dissociating automatic and consciously-controlled processes: Implications for diagnosis and rehabilitation of memory deficits. In D.J. Herrmann, C.L. McEvoy, C. Hertzog, P. Hertel, \& M.K. Johnson (Eds.), Basic and applied memory research: Theory in context (Vol. 1, pp. 161-193). Hillsdale, N.J: Lawrence Erlbaum Associates. 
Jacoby, L.L., Toth, J.P., \& Yonelinas, A.P. (1993). Separating conscious and unconscious influences of memory : Measuring recollection. Journal of Experimental Psychology: General, 122, 139-154.

Jacoby, L.L., Yonelinas, A.P., \& Jennings, J.M. (1997). The relation between conscious and unconscious (automatic) influences: A declaration of independence. In J. Cohen \& J.W. Schooler (Eds.), Scientific Approaches to the Question of Consciousness.(pp. 13-47). Hillsdale, N J: Erlbaum.

Jennings, J.M., Carello, E.A., Dagenbach, D., Rapp, S.R. Brenes, G.A., \& Atkinson, H. (2006). Improving recollection in individuals with mild cognitive impairment: Training and transfer effects. Poster session presented at the Cognitive Aging Conference, Georgia, Atlanta.

Jennings, J.M., \& Jacoby, L.L. (1993). Automatic versus intentional uses of memory: Aging, attention, and control. Psychology and Aging, 8, 283-293.

Jennings, J.M., \& Jacoby, L.L. (1997). An opposition procedure for detecting age-related deficits in recollection: telling effects of repetition. Psychology and Aging, 12, 352-361.

Jennings, J.M., \& Jacoby, L.L. (2003). Improving memory in older adults: Training recollection. Neuropsychological Rehabilitation, 13, 417-440.

Jennings, J.M., Webster, L.M., Kleykamp, B.A., \& Dagenbach, D. (2005). Recollection training and transfer effects in older adults: Successful use of a repetition-lag procedure. Aging, Neuropsychology and Cognition, $12,278-298$.

Jonides, J., Schumacher, E.H., Smith, E. E., Lauber, E. J., Awh, E., Minoshima, S., \& Koeppe, R. (1997). A Verbal working memory load affects regional brain activation as measured by PET. Journal of Cognitive Neuroscience, 9, 462-475.

Karbach, J., \& Kray, J. (2009). How use full is executive control training? Age differences in near and far transfer of task-switching training. Developmental Science, 12, 978-990.

Knight, R.G. (1998). Controlled and automatic memory processes in Alzheimer's disease. Cortex, 34, 427-435.

Koivisto, M., Portin, R., Seinelä, R., \& Rinne, J. (1998). Automatic influences of memory in Alzheimer's disease. Cortex, 34, 209-219.

Loewenstein, D.A., Acevedo, A., Czaja, S.J., \& Duara, R. (2004). Cognitive rehabilitation of mildly impaired Alzheimer disease patients on cholinesterase inhibitors. American Journal of Geriatric Psychiatry, 12, 395402. 
Lustig, C., \& Flegal, K. E. (2008). Targeting latent function: Encouraging effective encoding for successful memory training and transfer. Psychology and Aging, 23, 754-764.

Macmillan, N. A., \& Creelman, C. D. (2005). Detection Theory: A User's Guide. (2nd ed.). Mahwah, N.J.: Lawrence Erlbaum Associates.

Mandler, G. (1980). Recognizing: The judgment of previous occurrence. Psychological Review, 87, $252-271$.

Mattis, S. (1973). Dementia Rating Scale. Windsor, England: NFER-Nelson.

McKhann, G., Drachman, D., Folstein, M., Katzman, R., Price, D., \& Stadlan, E. M. (1984). Clinical diagnosis of Alzheimer's disease: Report of the NINCDS-ADRDA Work Group under the auspices of the Department of Health and Human Services Task Force on Alzheimer's Disease. Neurology, 34, 939-944.

Moscovitch, M. (1992). Memory and working-with-memory: a component process model based on modules and central systems. Journal of Cognitive Neuroscience, 4, 257-267.

Nyberg, L., Sandblom, J., Jones, S., Neely A.S., Petersson, K.M., Ingvar, M., et al. (2003). Neural correlates of training-related memory improvement in adulthood and aging. Proceedings of the National Academy of Sciences, 100, 13728-13733.

Persson, J., \& Reuter-Lorenz, P. A. (2008). Gaining control training executive function and far transfer of the ability to resolve interference. Psychological Science, 19, 881-888.

Posner, M. I. \& Snyder, C. R. R. (1975). Attention and cognitive control. In R. L. Solso (Ed.). Information Processing and Cognition: The Loyola Symposium (pp. 55-85), Hillsdale, NJ: Erlbaum.

Schneider, W., \& Shiffrin, R. M. (1977). Controlled and automatic human information processing: Detection, search, and attention. Psychological Review, 84, 1-66.

Smith, J.A., \& Knight, R.G. (2002). Memory processing in Alzheimer's disease. Neuropsychologia, 40, 666682.

Snodgrass, J. G., \& Corwin, J. (1988). Pragmatics of measuring recognition memory: Applications to dementia and amnesia. Journal of Experimental Psychology, General, 117, 34-50.

Snodgrass, J. G., \& Vanderwart, M. (1980). A standardized set of 260 pictures: Norms for name agreement, image agreement, familiarity, and visual complexity. Journal of Experimental Psychology: Human Learning and Memory, 6, 174-215.

Titov, N., \& Knight, R.G. (1997). Adult age differences in controlled and automatic memory processing. Psychology and Aging, 12, 419-428. 
Tounsi, H., Deweer, B., Ergis, A.M., Van der Linden, M. Pillon, B., Michon, A., \& Dubois, B. (1999). Sensitivity to semantic cuing: an index of episodic memory dysfunction in early Alzheimer disease. Alzheimer Disease and Associated Disorder, 13, 38-46.

Yesavage, J.A., Brink. T.L., Rose, T.L., Lum, O., Huang, V., Adey, M.B., \& Leirer, V.O. (1983). Development and validation of a geriatric depression screening scale: A preliminary report. Journal of Psychiatric Research, 17: 37-49.

Yonelinas, A.P. (2002). The nature of recollection and familiarity: A review of 30 years of research. Journal of Memory and Language, 46, 441-517.

Van der Linden, M., Coyette, F., Poitrenaud, J., et les membres du GREMEM (2004). L'épreuve de rappel libre/rappel indicé à 16 items (RL/Ri 16). In M. Van der Linden, S Adam, A. Agniel \& les membres du GRENEM (Eds.). L'évaluation des troubles de la mémoire. Présentation de quatre tests de mémoire épisodique (avec leur étalonnage) (pp. 25-47). Marseille : Solal.

Verhaeghen, P., Marcoen, A., \& Goossens, L. (1992). Improving memory performance in the aged through mnemonic training: A meta-analytic study. Psychology and Aging, 7, 242-251.

Waring, J. D., Chong, H., Wolk, D. A. \& Budson, A. E. (2008). Preserved metamemorial ability in patients with mild Alzheimer's disease: Shifting response bias. Brain and Cognition, 66, 32-39.

Wechsler, D. (1997). Wechsler Adult Intelligence Scale - Third Edition. New-York: The Psychological Corporation.

Westerberg, C.E., Paller, K.A., Weintraub, S., Mesulam, M.M., Holdstock, J.S. Mayes, A.R., \& Reber, P.J. (2006). When memory does not fail: Familiarity-based recognition in mild cognitive impairment and Alzheimer's disease. Neuropsychology, 20, 193-205. 


\section{Table 1}

Demographic and neuropsychological data for all patients

\begin{tabular}{|c|c|c|c|c|c|}
\hline & \multicolumn{3}{|c|}{ Groups } & \multicolumn{2}{|c|}{ ANOVA } \\
\hline & Recollection & Recognition & No contact & & \\
\hline & $(\mathrm{n}=12)$ & $(\mathrm{n}=12)$ & $(\mathrm{n}=12)$ & $F(2,33)$ & $p$ \\
\hline Age (years) & $81.58(2.78)$ & $82.67(1.63)$ & $79.33(3.85)$ & 1.08 & 0.352 \\
\hline Education (years) & $10.92(2.64)$ & $12.08(2.07)$ & $11.08(2.57)$ & $<1$ & 0.457 \\
\hline MMSE (/30) & $24(3.05)$ & $24.83(2.12)$ & $25.83(1.40)$ & 1.95 & 0.161 \\
\hline MDRS (/144) & $124(6.02)$ & $126.25(7.65)$ & $127.33(6.24)$ & $<1$ & 0.467 \\
\hline GDS (/30) & $4.50(2,24)$ & $4.33(1.78)$ & $4.42(1.88)$ & $<1$ & 0.979 \\
\hline Direct span & $5.17(0.94)$ & $5.33(0.89)$ & $5.42(1)$ & $<1$ & 0.804 \\
\hline Indirect span & $3.25(1.06)$ & $3.92(0.79)$ & $3.92(0.79)$ & 2.25 & 0.121 \\
\hline Formal fluency $2 \mathrm{mn}(\mathrm{P})$ & $12.67(5.61)$ & $14.67(5.47)$ & $14(5.80)$ & $<1$ & 0.678 \\
\hline Formal fluency $2 \mathrm{mn}(\mathrm{R})$ & $9.25(5.77)$ & $11.75(3.91)$ & $11(5.01)$ & $<1$ & 0.465 \\
\hline Semantic fluency $2 \mathrm{mn}$ (animals) & $12,08(3.55)$ & $15.17(5.44)$ & $14.67(6.58)$ & 1.15 & 0.328 \\
\hline Semantic fluency $2 \mathrm{mn}$ (fruits) & $10(3.19)$ & $13.50(4.32)$ & $12.17(4.28)$ & 2.38 & 0.108 \\
\hline DO 80 (/80) & $72.83(5.62)$ & $74.58(5.35)$ & $74.58(4.12)$ & $<1$ & 0.626 \\
\hline TMT A (second) & $69.92(30.40)$ & $59.17(20.22)$ & $74.58(4.12)$ & $<1$ & 0.474 \\
\hline TMT B (second) & $216(79.92)$ & $201.25(60.54)$ & $212.75(66,90)$ & $<1$ & 0.862 \\
\hline
\end{tabular}

Note. Groups were compared using one-way ANOVAs. Numbers in parentheses are standard deviations. MMSE Mini-Mental State Examination; MDRS _ Mattis Dementia Rating Scale; GDS_ Geriatric Depressive Scale; DO 80_Picture Naming Test; TMT_ Trail Making Test. Each verbal fluency was administered in 2 minutes. 


\section{Table 2}

Proportion of hits, false alarms, accuracy and estimates of bias $(\mathrm{C})$ for each training day for recollection training group

\begin{tabular}{|c|c|c|c|c|}
\hline \multirow{3}{*}{ Training days } & \multicolumn{4}{|c|}{ Recollection Training } \\
\hline & \multicolumn{4}{|c|}{$(\mathrm{n}=12)$} \\
\hline & Hits & False alarms & Accuracy $^{a}$ & Bias \\
\hline Day 1) & $0.52(.18)$ & $0.41(.12)$ & $0.22(.22)$ & $0.10(.30)$ \\
\hline Day 2 & $0.52(.15)$ & $0.43(.13)$ & $0.19(.19)$ & $0.07(.27)$ \\
\hline Day 3 & $0.53(.16)$ & $0.42(.12)$ & $0.17(.17)$ & $0.08(.30)$ \\
\hline Day 4 & $0.54(.17)$ & $0.42(.11)$ & $0.18(.18)$ & $0.06(.30)$ \\
\hline Day 5 & $0.54(.15)$ & $0.39(.11)$ & $0.16(.16)$ & $0.08(.28)$ \\
\hline Day 6 & $0.53(.16)$ & $0.43(.10)$ & $0.19(.19)$ & $0.05(.26)$ \\
\hline
\end{tabular}




\section{Table 3}

Proportion of hits, false alarms and accuracy for each training day for recognition practice group

\begin{tabular}{|c|c|c|c|}
\hline \multirow{3}{*}{ Training days } & \multicolumn{3}{|c|}{ Recognition Practice } \\
\hline & \multicolumn{3}{|c|}{$(n=12)$} \\
\hline & Hits & False alarms & Accuracy ${ }^{a}$ \\
\hline Day 1 & $0.52(.12)$ & $0.32(.10)$ & $0.20(.16)$ \\
\hline Day 2 & $0.53(.12)$ & $0.34(.10)$ & $0.20(.16)$ \\
\hline Day 3 & $0.55(.11)$ & $0.33(.11)$ & $0.22(.15)$ \\
\hline Day 4 & $0.54(.12)$ & $0.34(.11)$ & $0.20(.16)$ \\
\hline Day 5 & $0.56(.11)$ & $0.33(.10)$ & $0.23(.15)$ \\
\hline Day 6 & $0.56(.12)$ & $0.33(.11)$ & $0.23(.16)$ \\
\hline
\end{tabular}




\section{Table 4}

Means of pre and post training assessment performance on each transfer measure for the recollection training, recognition practice, and no contact groups

\begin{tabular}{|c|c|c|c|c|c|c|}
\hline \multirow{3}{*}{ Tasks } & \multicolumn{2}{|c|}{ Recollection Training } & \multicolumn{2}{|c|}{ Recognition Practice } & \multicolumn{2}{|c|}{ No Contact } \\
\hline & \multicolumn{2}{|c|}{$(\mathrm{n}=12)$} & \multicolumn{2}{|c|}{$(\mathrm{n}=12)$} & \multicolumn{2}{|c|}{$(n=12)$} \\
\hline & Pre & Post & Pre & Post & Pre & Post \\
\hline Reading Span (/6) & $2.92(1.78)$ & $3(1.35)$ & $3.25(1.96)$ & $3.17(1.34)$ & $3.17(1.27)$ & $3.25(1.54)$ \\
\hline \multicolumn{7}{|l|}{ N-back ${ }^{a}$} \\
\hline - 1-back ${ }^{\mathrm{a}}$ & $6.17(0.94)$ & $6.33(0.65)$ & $6.33(0.78)$ & $6.42(0.90)$ & $6.17(1.03)$ & $6.42(0.67)$ \\
\hline - 2-back ${ }^{a}$ & $2.50(2.28)$ & $3.75(2.22)$ & $3.17(1.75)$ & $2.75(2.33)$ & $2.92(1.68)$ & $3.08(1.62)$ \\
\hline$-3-b^{-a c k}{ }^{a}$ & $-0.25(2.45)$ & $-1(1.65)$ & $-0.50(2.43)$ & $-0.75(2.18)$ & $-1.08(1.93)$ & $-1.17(1.80)$ \\
\hline \multicolumn{7}{|l|}{ RL/RI 16} \\
\hline - Free recall (/48) & $10.83(4.51)$ & $10.58(4.81)$ & $12.83(4.69)$ & $134 .(67)$ & $11.92(4.78)$ & $11(4.41)$ \\
\hline - Free and cued recall (/48) & $30.58(9.73)$ & $30(9.05)$ & $32.42(9.52)$ & $32.33(8.38)$ & $29.67(8.25)$ & $28.67(8.51)$ \\
\hline - Free delay recall (/16) & $3.08(2.39)$ & $2.58(2.57)$ & $3.42(2.68)$ & $3.33(2.50)$ & $3.25(2.05)$ & $3.17(1.99)$ \\
\hline - Free and cued delay recall (/16) & $9.50(3.06)$ & $9.50(2.78)$ & $10.75(2.99)$ & $10.67(2.77)$ & $9.42(3.20)$ & $9.33(2.87)$ \\
\hline - Recognition (/16) & $13.92(1.62)$ & $14.75(1.14)$ & $14.50(1.62)$ & $15.33(1.23)$ & $14.58(1.44)$ & $14.50(1.68)$ \\
\hline DMS $48(/ 48)$ & $34.17(7.15)$ & $36.67(6.97)$ & $31(7.76)$ & $30.25(8.54)$ & $29.92(6.64)$ & $29.42(6.04)$ \\
\hline Source recognition (/30) & $16.83(4.63)$ & $18.92(3.60)$ & $17.25(4.83)$ & $16.50(4.66)$ & $16.42(3.80)$ & $16.08(3.68)$ \\
\hline
\end{tabular}


Fig. 1. Recollection training task's design. Each trial is made of 16 words-to-study that have to be recognized among 16 non-studied words repeated once. After each correct trial, the number of intervening words between repetitions (lag) is gradually increased.

STUDY PHASE

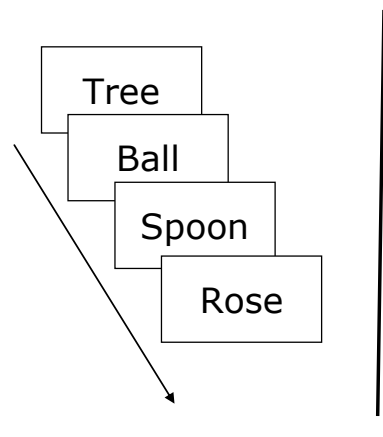

TEST PHASE

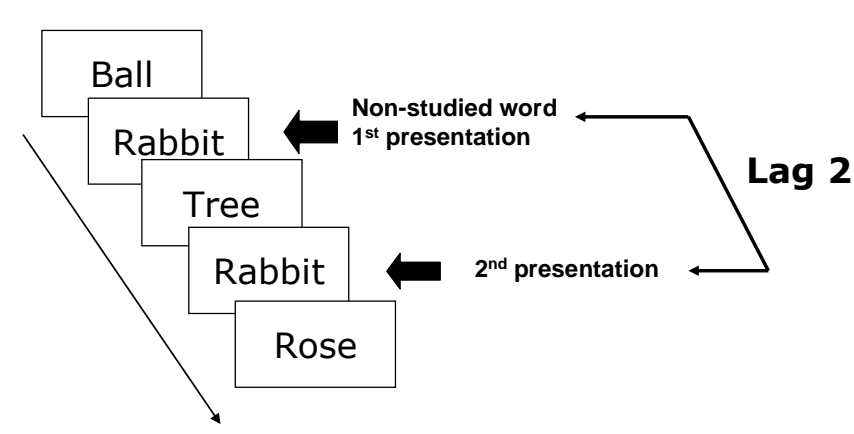


Fig. 2. Level of performance for each patient at the beginning and end of recollection training

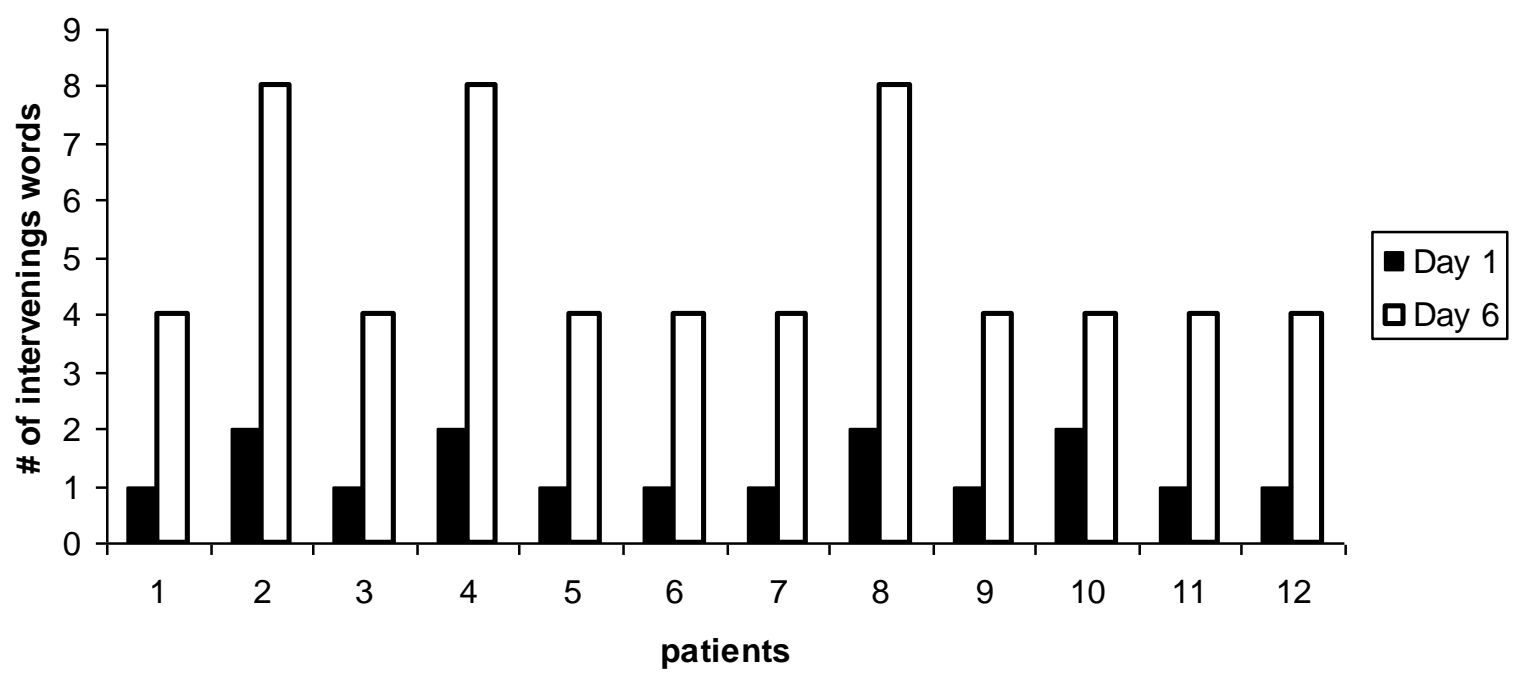

